\title{
A letalidade dos acidentes de trânsito nas rodovias federais brasileiras em 2016*
}

\author{
Gilvan Teles Barroso Junior ${ }^{\star \star}$ \\ Ana Carolina Soares Bertho ${ }^{* \star \star}$ \\ Alinne de Carvalho Veiga ${ }^{\star * *}$
}

\begin{abstract}
A preocupação com a mortalidade por acidentes de trânsito tem crescido em todo o mundo, sendo um importante problema de saúde pública e a principal causa de morte entre jovens de 15 a 29 anos de idade (WHO, 2015). No Brasil, em 2016, aproximadamente 37 mil pessoas morreram em decorrência de acidentes de trânsito, das quais 6.400 (17\%) vieram a óbito após ocorrências em rodovias federais. Tendo em vista a relevância dessas mortes, o objetivo do presente artigo é identificar os fatores associados à letalidade dos acidentes de trânsito nas rodovias federais brasileiras em 2016, considerando, além das características das vítimas, informações sobre 0 contexto de ocorrência desses eventos. Para tal finalidade, foi utilizado um modelo binomial de regressão logística. Os resultados indicam que, em média, as chances de um acidente de trânsito ser letal aumentam para indivíduos do sexo masculino, pedestres, com ocorrências na região Nordeste, aos domingos, durante a madrugada, nas curvas, nas áreas rurais e para vítimas com idades mais elevadas.
\end{abstract}

Palavras-chave: Acidentes de trânsito. Letalidade. Análise de regressão.

\footnotetext{
* O presente trabalho foi realizado com apoio da Coordenação de Aperfeiçoamento de Pessoal de Nível Superior - Brasil (Capes) - Código de Financiamento 001.

** Instituto Brasileiro de Geografia e Estatística (IBGE), Escola Nacional de Ciências Estatísticas (Ence), Rio de Janeiro-RJ, Brasil (gilvan.teles.junior@gmail.com; https://orcid.org/0000-0002-2974-8448).

${ }^{* * *}$ Instituto Brasileiro de Geografia e Estatística (IBGE), Escola Nacional de Ciências Estatísticas (Ence), Rio de Janeiro-RJ, Brasil (carolbertho@gmail.com; https://orcid.org/0000-0003-4822-1948).

*** Instituto Brasileiro de Geografia e Estatística (IBGE), Escola Nacional de Ciências Estatísticas (Ence), Rio de Janeiro-RJ, Brasil (alinne.veiga@ibge.gov.br; https://orcid.org/0000-0002-1611-2918).
} 


\section{Introdução}

Em todo o mundo a preocupação com os acidentes de trânsito tem se tornado cada vez maior à medida que este fenômeno vem se destacand o como um importante problema de saúde pública. Em 2015 a Organização Mundial da Saúde (OMS) apontou que cerca de 1,2 milhão de pessoas morrem por ano no mundo como consequência de acidentes de trânsito, os quais têm sido a principal causa de morte entre jovens de 15 a 29 anos de idade (WHO, 2015).

Segundo estimativas da OMS, a taxa de mortalidade por acidentes de trânsito, em 2013, correspondia a cerca de 24,1 óbitos por 100 mil habitantes nos países de renda baixa, 18,4 nos países de renda média - grupo ao qual o Brasil pertence - e 9,2 entre os de renda elevada (WHO, 2015). Dados do Sistema de Informações sobre Mortalidade (SIM) mostram que, nesse mesmo ano, a taxa brasileira foi de aproximadamente 21 óbitos por 100 mil habitantes, ${ }^{1}$ evidenciando que a mortalidade por esta causa é elevada em relação aos padrões mundiais.

Apenas em 2016, cerca de 37 mil pessoas morreram em decorrência de acidentes de trânsito no Brasil, sendo 6.400 (17\%) em rodovias federais.

Considerando-se tanto os custos diretos quanto os indiretos, em 2014, os acidentes de trânsito acarretaram um prejuízo de aproximadamente $\mathrm{R} \$ 40$ bilhões ao Brasil, sendo que aqueles ocorridos nas rodovias federais foram responsáveis por $\mathrm{R} \$ 12,3$ bilhões desse montante (BRASIL, 2015a).

Diante da importância dessas mortes, o objetivo do presente artigo é identificar os principais fatores associados à letalidade dos acidentes de trânsito nas rodovias federais brasileiras, segundo as características das vítimas e o contexto dos acidentes.

A letalidade de uma determinada doença representa a proporção de óbitos em relação ao total de doentes que a contraíram (PALMEIRA, 2000). Para o presente estudo, foi utilizada uma adaptação desse conceito, ou seja, trata-se da proporção de pessoas mortas em relação ao total de vítimas (pessoas feridas, independentemente da gravidade) dos acidentes. Assim, a probabilidade de uma vítima de acidente de trânsito morrer em consequência de tal evento é chamada de taxa de letalidade, variável resposta do modelo elaborado.

Todas as informações são provenientes do banco de dados da Polícia Rodoviária Federal (PRF) de 2016.

\section{Fatores associados aos acidentes de trânsito}

0 perfil das vítimas ${ }^{2}$ de acidentes de trânsito no Brasil, por sexo e idade, tem se mostrado consistente nos últimos anos. Homens com idades entre 20 e 40 anos são os que se

\footnotetext{
${ }^{1}$ Os dados referentes à população do Brasil em 2013, usados no denominador da taxa bruta de mortalidade por acidentes de trânsito, foram obtidos a partir de projeções populacionais realizadas pelo IBGE.

${ }^{2}$ Considera-se vítima de acidente de trânsito toda pessoa que sofreu alguma lesão física em razão deste, independentemente da gravidade.
} 
envolvem com mais frequência nesse tipo de ocorrência (DESLANDES; SILVA, 2000; LEGAY et al., 2012; LIMA; CRUZ JUNIOR, 2016). A letalidade tende a ser maior entre homens e mais elevada à medida que aumenta a idade da vítima (OLIVEIRA; MOTA; COSTA, 2008; MARÍN-LEÓN et al., 2012).

A condição de envolvimento das vítimas nos acidentes é outro fator de grande importância. 0 crescimento da frota de motos e a condução arriscada, comum especialmente no dia a dia dos motoboys, tiveram como consequência o aumento da participação de motociclistas entre as vítimas de acidentes de trânsito (ANDRADE; MELLO JORGE, 2000).

0 volume de motocicletas em circulação cresceu em ritmo acelerado no país, principalmente no Nordeste do país, onde a frota quadruplicou entre 2003 e 2014. Essa região concentrou a maior parte dos óbitos decorrentes de acidentes envolvendo motocicletas nas rodovias federais em 2014, com 44\% do total (BRASIL, 2015a).

Além do perfil das vítimas, conhecer os contextos nos quais os acidentes de trânsito ocorrem é de suma importância para a elaboração de ações e políticas públicas de prevenção. Alguns estudos apontam uma maior frequência aos finais de semana e no período noturno (BARROS et al., 2003; CABRAL; SOUZA; LIMA, 2011). Além disso, nas rodovias, alguns acidentes são mais recorrentes em tipos específicos de pista. Em 2004, entre as colisões frontais ocorridas em rodovias federais brasileiras, $81,75 \%$ aconteceram em pistas do tipo "simples", com tráfego nos dois sentidos e com ausência de separador físico entre os fluxos opostos (LIMA et al., 2008). Em 2014, os acidentes com as maiores parcelas de vítimas fatais nas rodovias federais brasileiras foram justamente as colisões frontais em conjunto com os atropelamentos de pedestres (BRASIL, 2015a).

0 uso do solo ${ }^{3}$ do local do acidente é um fator que está indiretamente associado à gravidade das lesões das vítimas. Acidentes em zonas rurais são, em geral, mais graves do que em áreas urbanas. Entre as possíveis razões estão a ausência de fiscalização e a prática de velocidades elevadas nesses locais (FARIA; BRAGA, 1999).

Um estudo realizado na Malásia, com base em dados de acidentes de trânsito ocorridos entre 2000 e 2011, mostrou que o número de mortes foi mais elevado nas áreas rurais (66\%) em comparação às urbanas (34\%) (DARMA; KARIM; ABDULLAH, 2017). Entre as explicações plausíveis para essa maior mortalidade estaria, entre outros fatores, a maior distância dos serviços de atendimento médico em áreas rurais, o que é crucial nos acidentes com ferimentos graves (RAKAUSKAS; WARD; GERBERICH, 2009).

\section{Técnicas usadas para o estudo dos acidentes de trânsito}

Diversas metodologias vêm sendo aplicadas para análise de dados de acidentes de trânsito, desde técnicas mais simples, como a comparação de taxas e razões por meio de

\footnotetext{
${ }^{3}$ De acordo com o dicionário de variáveis da PRF, a variável de uso do solo refere-se à descrição das características do local do acidente.
} 
análises descritivas, até as mais sofisticadas, como a estimação de modelos estatísticos espaciais e de regressão.

Beck, Dellinger e O'neil (2007), por exemplo, calcularam, para os Estados Unidos, taxas de acidentes fatais e não fatais envolvendo veículos motorizados, entre 1999 e 2003, usando o número de pessoas-viagem ${ }^{4}$ do ano de 2001 como medida de exposição ao risco de sofrer acidentes.

Santamariña-Rubio et al. (2014), por sua vez, estudaram as diferenças por sexo nas taxas de lesões por acidentes de trânsito na Catalunha, Espanha, entre 2004 e 2008, e utilizaram o tempo total gasto pelas pessoas nas viagens como medida de exposição.

Já Bacchieri e Barros (2011) analisaram a evolução das taxas de mortalidade por acidentes de trânsito, entre 1998 e 2008 no Brasil, empregando duas medidas distintas: o número de mortos por 100 mil habitantes e o número de mortos por 10 mil veículos em circulação no país.

Há estudos em que os autores optaram por calcular taxas por meio de diferentes denominadores para comparar os resultados obtidos. A partir de dados de registros médicos e de mobilidade do município de Rhône na França, Blaizot et al. (2013) utilizaram três medidas distintas de exposição aos acidentes de trânsito: o número total de viagens realizadas; a distância total percorrida; e o tempo total gasto pelas pessoas nas viagens.

Esses estudos mostram que a escolha do denominador para o cálculo das taxas de acidentes de trânsito tem reflexos importantes sobre os resultados. Porém, a adoção de metodologia baseada no cálculo de taxas que simulem de forma mais acurada a exposição ao risco está sujeita à disponibilidade dos dados. No caso da análise de acidentes de trânsito ocorridos no Brasil, em razão da ausência de fontes confiáveis para estimação de número de vítimas por quilômetros percorridos, são predominantes os estudos que usam a população, ou, com menor frequência, a frota de automóveis ou motocicletas como denominador.

Na literatura nacional, há um volume considerável de estudos em que os autores apresentam basicamente uma análise descritiva de indicadores. Ainda que seja uma abordagem simples, os resultados produzidos possibilitam a identificação dos principais aspectos do fenômeno de interesse. Dentre esses trabalhos sobre acidentes de trânsito estão os de Ganne (2010), Malta et al. (2011), Bacchieri e Barros (2011), Legay et al. (2012), Marín-León et al. (2012) e Brasil (2015a).

Outro conjunto de técnicas estatísticas comumente utilizadas na análise de dados de acidentes de trânsito corresponde aos modelos lineares generalizados, dentre os quais o mais utilizado tem sido o modelo de Poisson. Lima e Cruz Junior (2016) ajustaram um modelo desse tipo para analisar o efeito de variáveis comportamentais sobre a ocorrência de acidentes de trânsito entre condutores de automóveis e motocicletas no Brasil em 2013.

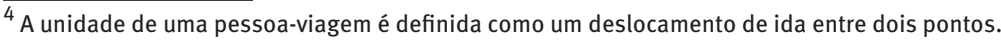


Paixão et al. (2015), por sua vez, estimaram um modelo de regressão de Poisson para traçar o perfil das vítimas fatais de acidentes de trânsito em Belo Horizonte, Minas Gerais, em 2010 e 2011.

Outros dois tipos de distribuições de probabilidade utilizados com menor frequência na estimação de modelos lineares generalizados que visam a análise de acidentes de trânsito são as distribuições binomial e a binomial negativa.

Oliveira e Sousa (2012) empregaram um modelo binomial logístico para investigar os fatores associados ao óbito de motociclistas nas ocorrências de trânsito em 2004, na cidade de Maringá, Paraná.

Blaizot et al. (2013) compararam as taxas de incidência de feridos em acidentes de trânsito, segundo o tipo de modal utilizado, sexo, faixa etária e local, por meio de um modelo estatístico que assumia distribuição binomial negativa na contagem destes eventos.

A maior parte dos estudos sobre acidentes de trânsito faz apenas análises descritivas considerando características gerais das vítimas. 0 levantamento bibliográfico apresentado mostra que o uso de ferramentas estatísticas que incluam as informações do contexto no qual ocorreu o acidente enriquece a análise e dá subsídios para a elaboração de políticas de prevenção mais específicas.

O presente estudo utilizou o modelo de regressão binomial. A justificativa será explicitada a seguir.

\section{Materiais e métodos}

Para a análise da letalidade dos acidentes de trânsito nas rodovias federais brasileiras, foi utilizada a base de dados de acidentes da Polícia Rodoviária Federal (PRF), referente a 2016, com abrangência nacional e disponibilizada para download no site da própria instituição. Estão disponíveis informações sobre as vítimas, como sexo e idade, além de um amplo conjunto de variáveis relacionadas ao contexto de ocorrência dos acidentes.

Os registros dessa base são feitos de duas formas. Para acidentes em que nenhum indivíduo envolvido apresentou lesões, sem a ocorrência de dano social ${ }^{5}$ e quando nenhum dos condutores estava sob influência de substância psicoativa, o registro é feito a partir da declaração eletrônica de acidente de trânsito (e-DAT), preenchida via internet pelos envolvidos até 15 dias após o acidente. ${ }^{6}$ Já no caso de algum envolvido ter se lesionado, algum condutor estiver sob efeito de substância psicoativa, ou o acidente ter acarretado dano social, o registro é feito por meio do Boletim de Acidente de Trânsito (BAT), documento oficial da PRF que é preenchido por um policial rodoviário ou por uma comissão designada (BRASIL, 2015b).

\footnotetext{
$\overline{5}$ Um acidente com dano social é aquele que extrapola a seara dos direitos das pessoas envolvidas na ocorrência, vindo a afetar a coletividade, ou seja, acidentes dos quais resultam interrupções de pista, danos ao patrimônio público ou ao meio ambiente, envolvendo veículos oficiais ou ocorrência de algum crime (BRASIL. Lei no 9.503, 1997).

${ }^{6}$ As declarações de indivíduos distintos envolvidos no mesmo acidente são unificadas e tratadas como uma só ocorrência. Esta unificação é de responsabilidade da PRF.
} 
Entre as vantagens oferecidas pelos dados da PRF, destacam-se a variedade de variáveis relativas ao contexto em que os acidentes de trânsito ocorreram e o baixo volume de informações faltantes ou não declaradas em relação a outras bases de dados, tais como o Sistema de Informações sobre Mortalidade (SIM).

A principal desvantagem identificada da base de dados da PRF é a baixa qualidade de seus metadados, que são muito pouco informativos. Há a possibilidade de se recorrer ao manual MPO-015, em que constam instruções que devem ser seguidas pelos policiais rodoviários ao preencher algumas das informações dessa base de dados. Porém, neste manual não existem instruções para o preenchimento de todos os campos presentes na base de dados, como, por exemplo, a condição meteorológica.

A base de dados da PRF possui também a limitação de captar apenas os óbitos que ocorreram no local do acidente. A OMS recomenda que as vítimas sejam acompanhadas por 30 dias e que, caso venham a óbito dentro deste período por consequência do agravamento das lesões sofridas, a causa atribuída às mortes seja o acidente de trânsito (OMS, 1984). Tal limitação é inerente à base de dados. Entretanto, avalia-se que o sub-registro dos óbitos na base da PRF (em razão do não acompanhamento dos feridos no período subsequente à ocorrência) seja mais baixo do que o dos acidentes em geral, pois nas rodovias os limites de velocidade são mais elevados do que nas vias públicas urbanas e os acidentes tenderiam a ser mais graves, reduzindo a proporção de pessoas que chegariam a ser socorridas antes de vir a óbito.

Para que os dados atendessem às necessidades da presente pesquisa, foram realizados alguns ajustes e tratamentos. Inicialmente a base continha 216.261 registros. Desse total, foram excluídos aqueles referentes a indivíduos que não haviam sido expostos ao risco de morte, isto é, os ilesos (112.305, ou seja, 51,9\% dos indivíduos). Em seguida, também foram desconsiderados os registros que continham dados inválidos para alguma das variáveis que seriam utilizadas na análise ou cuja categoria preenchida tenha sido "ignorado", "não identificado", "NA" ou “indefinido". Por fim, também foram excluídos os registros de indivíduos com mais de 100 anos de idade e de condutores de veículos motorizados com menos de dez anos de idade, por serem potenciais casos de erro de preenchimento. Após essas exclusões, restaram 77.241 registros ( $35,7 \%$ do total), que incluem as pessoas que se feriram em acidentes, independentemente do grau de severidade - ou seja, desde os que tiveram ferimentos leves até as pessoas que morreram no acidente.

A operacionalização da análise da letalidade dos acidentes de trânsito foi feita por meio da adoção da variável dicotômica morto ou sobrevivente. Tendo em vista essa característica da variável resposta, o modelo estatístico mais adequado para tal propósito é o binomial com função de ligação logit, cuja variável resposta possui distribuição Bernoulli. Além da característica dicotômica da variável resposta, optou-se por este modelo por ser um método de fácil implementação e interpretação.

Os dados da PRF para 2016 contêm, originalmente, 28 variáveis, das quais 13 foram selecionadas para serem usadas na análise: sexo da vítima (masculino e feminino); idade 
da vítima; tipo de envolvimento da vítima no acidente; tipo de veículo; tipo de acidente; tipo de pista (simples, dupla e múltipla); tipo de traçado da via no local do acidente (reta, cruzamento e curva); dia da semana; hora do acidente; uso do solo no local do acidente (urbano e rural); unidade da federação (posteriormente agregadas em regiões brasileiras); e estado físico da vítima após o acidente (ferido leve, ferido grave e morto, posteriormente unificados apenas em vivo ou morto).

Havia, ainda, outras duas variáveis de interesse - condição meteorológica e causa do acidente - que não foram incluídas na análise, pois os critérios de preenchimento são pouco claros. No manual de atendimento de acidentes de trânsito da Polícia Rodoviária Federal (BRASIL, 2015b), não há instruções sobre como declarar ${ }^{7}$ a condição meteorológica. Quanto à causa do acidente, as categorias “falta de atenção" e "outras" totalizaram mais de $50 \%$ das causas, o que levou à hipótese de que estas duas categorias estejam inflacionadas, concentrando possivelmente registros cuja causa dos acidentes não pôde ser identificada com precisão pelo policial rodoviário.

Foram feitas algumas modificações nas 13 variáveis selecionadas, em alguns casos por questão de simplificação e, em outros, para que atendessem melhor ao propósito da análise.

As variáveis tipo de veículo e tipo de envolvido foram combinadas para criar a variável condição de envolvimento, que identifica a forma como se deu a participação da vítima no acidente. Em suas categorias não foram feitas distinções entre condutor e passageiro em casos em que a vítima se envolveu no acidente como ocupante de um veículo, mas o tipo de veículo foi identificado. As vítimas envolvidas nos acidentes de trânsito na condição de ocupantes de motocicleta e motoneta foram agrupadas em uma mesma categoria, os ocupantes de caminhonete e camioneta foram considerados ocupantes de automóveis e os ocupantes de caminhão, caminhão-trator, caminhão-tanque, reboque e semirreboque foram considerados ocupantes de caminhão.

A unidade da federação foi empregada para criar a variável região, cujas categorias corresponderam às macrorregiões das quais cada unidade da federação faz parte.

Para a variável horário do acidente, originalmente no formato "hh:mm:ss", foram criadas as seguintes categorias possíveis: manhã (06:00:01 a 12:00:00); tarde (12:00:01 a 18:00:00); noite (18:00:01 a 00:00:00); e madrugada (00:00:01 a 06:00:00).

Quanto ao tipo de acidente, as categorias capotamento e tombamento foram unidas em uma única categoria que foi chamada de capotamento ou tombamento e as categorias colisão com objeto fixo, colisão com objeto móvel, incêndio, danos eventuais e derramamento de carga foram todas inseridas na categoria outros.

Por fim, a variável estado físico das vítimas foi simplificada para ser utilizada como variável resposta do modelo estatístico e as categorias ferido leve e ferido grave foram agrupadas em uma nova categoria nomeada de sobreviventes. Os procedimentos descritos encontram-se resumidos no Anexo 1. Para ajuste do modelo foi utilizada a função "glm"

\footnotetext{
${ }^{7}$ Por exemplo: não é possível identificar a diferença entre as categorias "céu claro" e "sol". A categoria "vento" tampouco é informativa, dado que esse fenômeno pode ocorrer concomitantemente com as categorias anteriores.
} 
do software $R$ (versão 3.4.2), a qual utiliza o método da máxima verossimilhança para estimação dos parâmetros do modelo.

Cabe destacar ainda que, para todos os testes estatísticos, foi empregado o nível de confiança de $95 \%$.

Feitas as alterações mencionadas, foram definidas 11 possíveis variáveis explicativas para o modelo: sexo; idade; condição de envolvimento da vítima; tipo de acidente; causa do acidente; tipo de pista; traçado do trecho da via; dia da semana; hora de ocorrência do acidente; uso do solo; e região do país.

As variáveis explicativas utilizadas no ajuste do modelo estatístico apresentam as seguintes distribuições:

- sexo - masculino (72,2\%) e feminino ( $27,8 \%)$;

- idade (em anos completos, categorizada) - 0 a 14 anos (4,7\%), 15 a 30 anos (35,7\%), 30 a 44 anos (33,6\%), 45 a 59 anos (18,1\%) e 60 anos e mais (7,9\%);

- condição de envolvimento (participação do indivíduo no acidente) - ocupante de automóvel (39,6\%), ocupante de bicicleta (2\%), ocupante de caminhão $(8,1 \%)$, ocupante de motocicleta (30,1\%), ocupante de ônibus ( $2,9 \%)$, pedestre $(3,6 \%$ ) e outros $(13,7 \%)$;

- tipo de pista - simples $(58,4 \%)$, dupla $(35,8 \%)$ e múltipla $(5,8 \%)$;

- tipo de acidente - atropelamento de animal (1,5\%), atropelamento de pessoa (4,2\%), colisão frontal (11,9\%), colisão lateral (10,9\%), colisão transversal $(13,8 \%)$, colisão traseira (17,2\%), capotamento ou tombamento $(11,5 \%)$, queda de veículo $(8,1 \%)$, saída da pista $(14,5 \%)$ e outros $(6,4 \%)$;

- traçado da via - cruzamento (5,5\%), reta $(71,6 \%)$ e curva $(22,9 \%)$;

- dia da semana - segunda (13,1\%), terça (11,6\%), quarta (11,8\%), quinta (12,6\%), sexta (15\%), sábado (17,8\%) e domingo (18,1\%);

- fase do dia - manhã (6:01 às 12:00) (27,4\%), tarde (12:01 às 18:00) (31,6\%), noite (18:01 às 0:00) $(28,9 \%)$ e madrugada (0:01 a 6:00) $(12,1 \%)$;

- uso do solo - urbano (46\%) e rural (54\%);

- região: Centro-Oeste (11,7\%), Norte (5,4\%), Nordeste (21\%), Sul (29\%) e Sudeste $(32,9 \%)$;

- estado físico (do indivíduo após seu envolvimento no acidente) - vivo (92,9\%) e morto $(7,1 \%)$.

A partir do modelo nulo, as variáveis explicativas foram inseridas uma a uma no modelo e, dependendo da sua significância (considerando-se o nível de 5\%), era mantida ou retirada do modelo e uma nova variável era inserida no passo seguinte. Esse procedimento foi repetido até que todas as varáveis explicativas tivessem sido testadas.

Em seguida, investigou-se a necessidade de inclusão de termos de interação no modelo. A interação entre as variáveis sexo e idade foi investigada por ser comum em estudos na 
área da saúde e da demografia. A interação entre condição de envolvimento e sexo também foi examinada, pois em um estudo foi observado que a distribuição das categorias de condição de envolvimento das vítimas de acidentes de trânsito varia segundo o sexo (MALTA et al., 2011). Por fim, também foi averiguado se havia interação entre as variáveis tipo de pista e tipo de acidente, uma vez que acidentes do tipo colisão frontal tendem a ser mais frequentes em pistas do tipo simples (LIMA et al., 2008).

Após a realização dos procedimentos descritos, chegou-se ao modelo final, que foi submetido ao teste de bondade de ajuste de Hosmer e Lemeshow (1980). A partir de tal teste não foram encontradas evidências estatísticas de que o modelo estivesse mal especificado ou mal ajustado aos dados.

\section{Resultados}

Os resultados da estimação do modelo final encontram-se no Anexo 2. A Tabela 1 apresenta as razões de chance calculadas para todas as variáveis explicativas do modelo 1 , com exceção de idade e daquelas com termos de interação, as quais serão discutidas posteriormente. Para a interpretação dos resultados, é importante ressaltar que as razões de chances são calculadas para cada variável supondo constantes todas as demais.

A razão de chances da variável sexo mostra que as chances de um acidente em uma rodovia federal ser letal são, em média, 44\% maiores para homens em relação às mulheres.

Quanto à condição de envolvimento das vítimas nos acidentes, em média, essas chances são 8,49 vezes maiores para os pedestres, 2,71 vezes para os ciclistas, $90 \%$ maiores para os ocupantes de motocicleta e $41 \%$ para os ocupantes de caminhão, em relação aos ocupantes de automóvel. Já para os ocupantes de ônibus, estas chances são $46 \%$ menores.

Verifica-se também que as chances de um acidente ser letal são, em média, $78 \%$ maiores para vítimas de ocorrências na região Nordeste, 58\% no Norte, $44 \%$ no Centro-Oeste e $10 \%$ no Sul, em comparação ao Sudeste.

Quanto aos dias da semana, as chances de um acidente de trânsito ser letal são, em média, 35\% maiores aos domingos e 18\% aos sábados, em comparação à segunda-feira. Porém, não há diferença significava entre a letalidade dos acidentes que ocorreram nos demais dias da semana quando comparados à segunda-feira.

Quanto à fase do dia, os acidentes apresentam, em média, chances 1,23 vezes maiores de serem letais durante a madrugada e $40 \%$ maiores durante a noite, em relação à manhã. Ao nível de significância de $5 \%$, não há diferença entre as chances de um acidente ser letal durante a tarde em comparação à manhã.

Além disso, em média, essas chances de letalidade são 1,29 vezes maiores em acidentes em curvas e 1,22 em retas, em comparação com acidentes em cruzamentos.

Quanto ao uso do solo, verificou-se que, em média, as chances de um acidente de trânsito ser letal são 1,41 vezes maiores em áreas rurais dos que nas urbanas. 
TABELA 1

Razões de chance de óbito das vítimas dos acidentes de trânsito nas rodovias federais, referentes às variáveis explicativas do modelo final (exceto idade, tipo de pista e tipo de acidente) Brasil - 2016

\begin{tabular}{|c|c|c|c|c|c|}
\hline \multirow[b]{2}{*}{ Variáveis } & \multirow[b]{2}{*}{$\beta$} & \multicolumn{3}{|c|}{ IC de $95 \%$ para $\exp (\beta)$} & \multirow{2}{*}{$\begin{array}{l}\text { Aumento nas } \\
\text { chances de } \\
\text { letalidade (\%) }\end{array}$} \\
\hline & & $\exp (\beta)$ & LI & LS & \\
\hline \multicolumn{6}{|l|}{ Sexo (ref: feminino) } \\
\hline Masculino & 0,36 & 1,44 & 1,34 & 1,55 & 44,0 \\
\hline \multicolumn{6}{|c|}{ Condição de envolvimento (ref: ocupante de automóvel) } \\
\hline Ocupante de bicicleta & 1,31 & 3,71 & 3,08 & 4,46 & 271,0 \\
\hline Ocupante de caminhão & 0,34 & 1,41 & 1,26 & 1,57 & 41,0 \\
\hline Ocupante de motocicleta & 0,64 & 1,90 & 1,74 & 2,07 & 90,0 \\
\hline Ocupante de ônibus & $-0,61$ & 0,54 & 0,44 & 0,67 & $-46,0$ \\
\hline Pedestre & 2,25 & 9,49 & 7,22 & 12,47 & 849,0 \\
\hline Outros & 0,34 & 1,41 & 1,11 & 1,78 & 41,0 \\
\hline \multicolumn{6}{|l|}{ Região (ref: Sudeste) } \\
\hline Norte & 0,46 & 1,58 & 1,39 & 1,80 & 58,0 \\
\hline Centro-Oeste & 0,36 & 1,44 & 1,30 & 1,59 & 44,0 \\
\hline Nordeste & 0,58 & 1,78 & 1,65 & 1,93 & 78,0 \\
\hline Sul & 0,10 & 1,10 & 1,02 & 1,20 & 10,0 \\
\hline \multicolumn{6}{|l|}{ Dia da semana (ref: segunda-feira) } \\
\hline Terça-feira & $-0,01$ & 0,99 & 0,87 & 1,12 & $-1,0$ \\
\hline Quarta-feira & 0,08 & 1,09 & 0,96 & 1,23 & 9,0 \\
\hline Quinta-feira & 0,06 & 1,06 & 0,94 & 1,20 & 6,0 \\
\hline Sexta-feira & 0,04 & 1,04 & 0,93 & 1,17 & 4,0 \\
\hline Sábado & 0,17 & 1,18 & 1,06 & 1,32 & 18,0 \\
\hline Domingo & 0,30 & 1,35 & 1,22 & 1,50 & 35,0 \\
\hline \multicolumn{6}{|c|}{ Fase do dia (ref: manhã - 6:00 a 12:00) } \\
\hline Tarde - 12:00 a 18:00 & $-0,00$ & 1,00 & 0,92 & 1,09 & 0,0 \\
\hline Noite - 18:00 a 0:00 & 0,34 & 1,40 & 1,29 & 1,52 & 40,0 \\
\hline Madrugada - 0:00 a 6:00 & 0,80 & 2,23 & 2,03 & 2,45 & 123,0 \\
\hline \multicolumn{6}{|l|}{ Traçado da via (ref: cruzamento) } \\
\hline Reta & 0,80 & 2,22 & 1,80 & 2,74 & 122,0 \\
\hline Curva & 0,83 & 2,29 & 1,84 & 2,84 & 129,0 \\
\hline \multicolumn{6}{|l|}{ Uso do solo (ref: urbano) } \\
\hline Rural & 0,88 & 2,41 & 2,24 & 2,60 & 141,0 \\
\hline
\end{tabular}

Fonte: Polícia Rodoviária Federal, 2016.

O Gráfico 1 mostra as probabilidades de morte estimadas pelo modelo final segundo a idade das vítimas. Observa-se que as probabilidades de óbito preditas pelo modelo são decrescentes no intervalo de zero a 10 anos de idade e crescentes a partir de dez anos, de maneira que a letalidade tem seu ápice entre os idosos. 
GRÁFICO 1

Probabilidades de óbito das vítimas dos acidentes de trânsito nas rodovias federais preditas pelo modelo final, segundo idade

Brasil - 2016

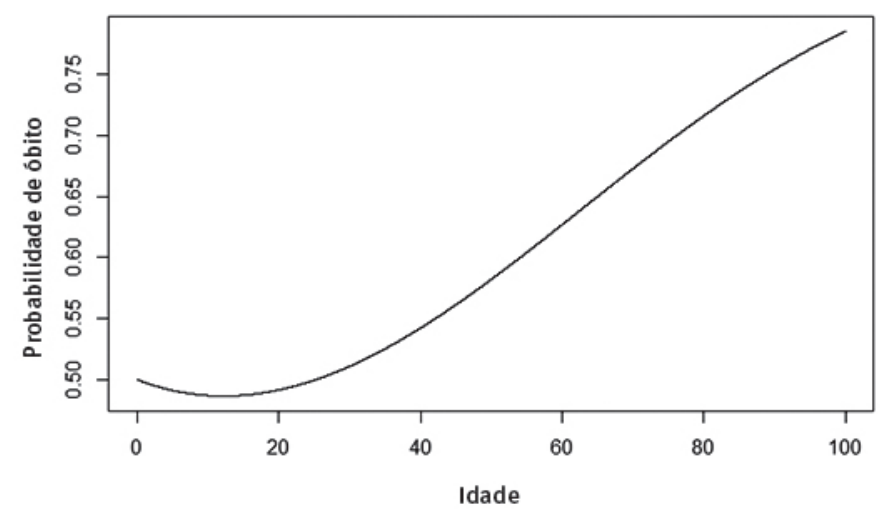

Fonte: Polícia Rodoviária Federal, 2016.

Nota: Demais variáveis explicativas do modelo fixadas nas categorias de referência.

O Gráfico 2 apresenta os intervalos de confiança de 95\% para as médias das probabilidades de óbito, estimadas para as vítimas dos acidentes de trânsito, por tipo de acidente e de pista. Em geral, as maiores médias dessas probabilidades correspondem a acidentes ocorridos em pistas simples, exceto para os atropelamentos de pessoas. Nesse caso particular, a média das probabilidades é mais elevada em pistas duplas. Verifica-se ainda que, em geral, as menores médias de probabilidades de óbito ocorrem em pistas múltiplas, com exceção de acidentes do tipo colisão lateral e queda de veículo, para os quais as médias das probabilidades são menores em pistas duplas.

Para analisar isoladamente o efeito do contexto dos acidentes na letalidade das vítimas, foram comparadas, na Tabela 2, as chances de letalidade de duas vítimas hipotéticas de acidentes distintos, ambas com características idênticas, mas uma delas se envolvendo em um acidente com características de contexto associadas a altas probabilidades de morte e a outra em um acidente com características associadas a baixas probabilidades de morte.

Como mostra a Tabela 2, em média, as chances de morte para uma vítima de um acidente com características de contexto associadas a elevadas probabilidades de óbito são cerca de 161 vezes maiores, em comparação a uma outra vítima de acidente com características associadas a baixas probabilidades de óbito. 


\section{GRÁFICO 2}

Intervalos de confiança de $95 \%$ para as médias das probabilidades de óbito das vítimas de acidentes de trânsito nas rodovias federais estimadas pelo modelo, por tipo de acidente, segundo tipo de pista

Brasil - 2016

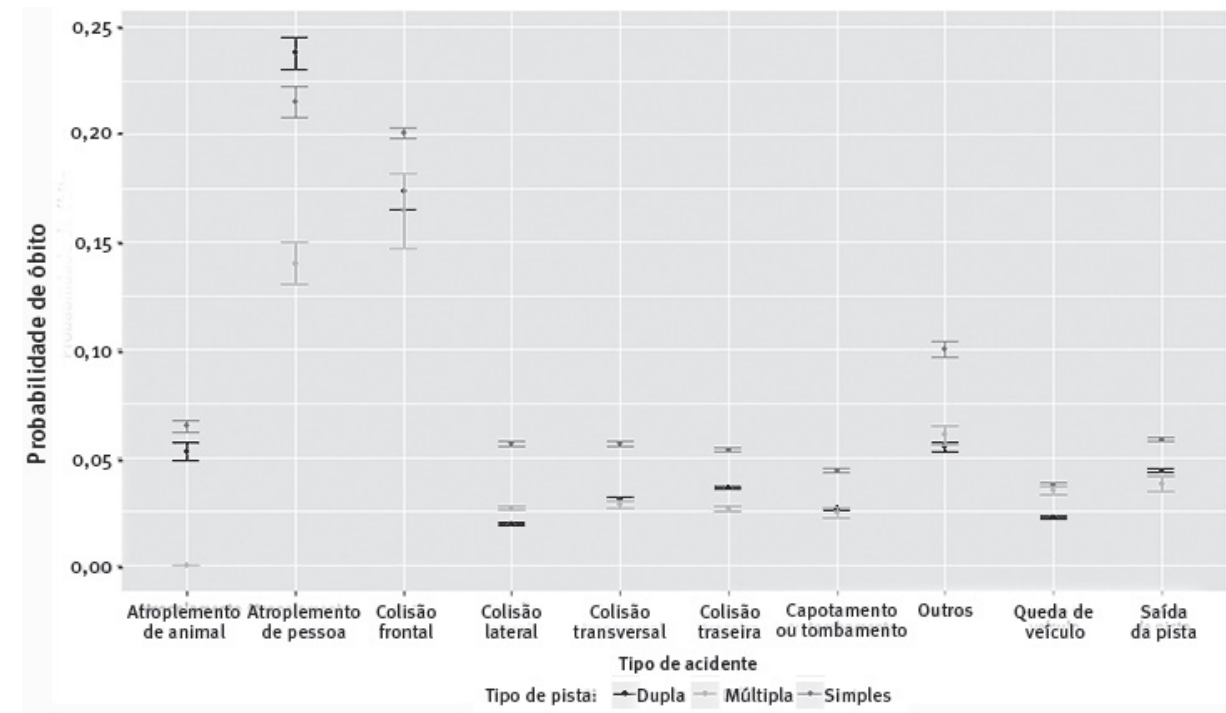

Fonte: Polícia Rodoviária Federal, 2016.

TABELA 2

Razão de chances para a letalidade de vítimas de acidentes nas rodovias federais com características de contexto associadas a probabilidades de morte elevadas e baixas

\begin{tabular}{lll}
\hline \multicolumn{1}{c}{$\begin{array}{c}\text { Variáveis de contexto dos } \\
\text { acidentes }\end{array}$} & \multicolumn{2}{c}{ Categorias associadas a: } \\
\cline { 2 - 3 } & Letalidade maior (a) & Letalidade menor (b) \\
\hline Região & Nordeste & Sudeste \\
Tipo de acidente & Colisão frontal & Colisão traseira \\
Tipo de pista & Pista simples & Pista múltipla \\
Dia da semana & Domingo & Segunda-feira \\
Fase do dia & Madrugada & Manhã \\
Traçado da via & Reta & Cruzamento \\
Uso do solo & Rural & Urbano \\
\hline Razão de chances $(\mathbf{a} / \mathbf{b})$ & & $\mathbf{1 6 0 , 6 4}$ \\
\hline
\end{tabular}

Fonte: Polícia Rodoviária Federal, 2016.

De maneira análoga, também se buscou analisar separadamente o impacto das características das vítimas nas probabilidades de morte. Assim, foram comparadas as chances de letalidade de duas vítimas hipotéticas de acidentes de trânsito com exatamente as mesmas características de contexto, sendo uma das vítimas com características associadas a probabilidades de morte elevadas e outra com características associadas a baixas 
probabilidades de morte. Os resultados da Tabela 3 mostram que, em média, as chances de morte para uma vítima que possui características associadas a elevadas probabilidades de óbito em decorrência de um acidente de trânsito são aproximadamente 66 vezes maiores em comparação àquela com características associadas a baixas probabilidades de morte.

TABELA 3

Razão de chances para a letalidade de vítimas de acidentes de trânsito nas rodovias federais com características associadas a probabilidades de morte elevadas e baixas

\begin{tabular}{lll}
\hline \multirow{2}{*}{$\begin{array}{c}\text { Variáveis de caracterização das } \\
\text { vítimas }\end{array}$} & \multicolumn{2}{c}{ Valores associadas a: } \\
\cline { 2 - 3 } & Masculino & Letalidade menor (b) \\
\hline Sexo & 80 anos & Feminino \\
Idade & Pedestre & 20 anos \\
Condição de envolvimento & \multicolumn{2}{c}{ Ocupante de ônibus } \\
\hline Razão de chances $(\mathbf{a} / \mathbf{b})$ & \multicolumn{6}{c}{$\mathbf{6 5 , 6 3}$} \\
\hline
\end{tabular}

Fonte: Polícia Rodoviária Federal, 2016.

\section{Discussão}

Em diversos aspectos a presente pesquisa corrobora com resultados já consolidados na literatura. 0 primeiro deles é a maior taxa de letalidade entre os homens em relação às mulheres. Oliveira, Mota e Costa (2008), por exemplo, apontam que mais de $70 \%$ das vítimas de acidentes de trânsito registrados em Salvador (Bahia), entre 1991 e 2000, eram homens, proporção que ultrapassa $80 \%$ entre os mortos.

$\mathrm{Na}$ análise segundo a idade das vítimas, verificou-se que as probabilidades de morte são mais elevadas para os idosos, resultado que é coerente com outros apontados na literatura. Em pesquisa realizada nos Estados Unidos, Massie, Campbell e Williams (1995) observaram que as taxas de letalidade em acidentes de trânsito são mais altas para idosos, ainda que as taxas de vitimização em acidentes em geral sejam maiores para os mais jovens.

Outro resultado encontrado foi o risco maior de morte para os pedestres, seguidos pelos ciclistas e os ocupantes de motocicleta, em comparação aos ocupantes de automóveis. Esse risco elevado para tais grupos é frequentemente abordado na literatura e a Organização Mundial de Saúde (WHO, 2015) usa o termo “usuários vulneráveis do sistema viário" para designá-los, uma vez que, em caso de colisão, têm o corpo mais exposto, diferentemente do que ocorre com os ocupantes de automóveis ou ônibus, que estão protegidos pela estrutura metálica dos veículos. Kong e Yang (2010) identificaram que o risco de morte de um pedestre é crescente de acordo com a velocidade dos veículos, sendo que em velocidades acima de $80 \mathrm{~km} / \mathrm{h}$ é raro que o pedestre sobreviva ao acidente.

Já a análise por regiões do Brasil mostra que, em comparação ao Sudeste, as chances de morte em acidentes de trânsito nas rodovias federais são maiores no Nordeste, Norte, Centro-Oeste e Sul, nessa ordem. Esse resultado difere daquele encontrado por Mello Jorge (2013) ao analisar as taxas de mortalidade dos acidentes de trânsito ocorridos em 
2013. ${ }^{8}$ No entanto, deve-se destacar que os estudos foram realizados a partir de universos e indicadores diferentes (Mello Jorge investiga o total dos acidentes de trânsito, incluindo os que ocorrem nas vias urbanas, e utiliza taxas de mortalidade).

A presente pesquisa identificou que as chances de um acidente ser letal são maiores aos finais de semana (em comparação à segunda-feira) e nos períodos da madrugada e da noite (em relação à manhã). Há autores que apontam a existência de maior propensão ao consumo de bebidas alcóolicas ${ }^{9}$ durante os finais de semana e no período noturno, com clara associação aos momentos de lazer (ABREU et al., 2010). Esta seria uma possível explicação para a letalidade mais elevada em acidentes que ocorreram aos finais de semana e durante a "noite" e a "madrugada", visto que a ingestão de álcool está associada a maiores riscos de letalidade no trânsito (WHO, 2015). Quanto à fase do dia, há ainda a questão de a visibilidade ser menor durante o período noturno (MORAIS et al., 2014).

No que se refere ao uso do solo, verificou-se maior letalidade nos acidentes de trânsito ocorridos em áreas rurais em relação às urbanas. Tal resultado não é exclusivo do Brasil. Em estudo realizado nos Estados Unidos, Zwerling et al. (2005) também identificaram maiores taxas de mortalidade nos acidentes de trânsito ocorridos em zonas rurais.

\section{Considerações finais}

Ainda que a produção acadêmica voltada à análise de acidentes de trânsito seja vasta, são poucos os estudos que investigam um conjunto amplo de fatores relacionados não somente às vítimas, mas também ao contexto de ocorrência.

Para a produção do presente artigo foi necessário compilar trabalhos de áreas de estudo variadas para consolidar um arcabouço a fim de orientar a escolha das variáveis explicativas que seriam testadas na estimação do modelo estatístico para a letalidade dos acidentes de trânsito nas rodovias federais brasileiras.

A base de dados da PRF se destaca pela possibilidade de análise combinada de variáveis das vítimas e do contexto de ocorrência dos acidentes, ainda que haja limitações já mencionadas.

0 modelo estimado para a letalidade dos acidentes de trânsito apresentou um bom ajuste e produziu resultados consistentes com a literatura.

Além de corroborar com resultados já consolidados e há muito conhecidos na produção nacional e internacional, o presente artigo traz como contribuição a análise combinada de fatores das vítimas e de contexto. Verificou-se que, para vítimas com características idênticas, as chances de um acidente de trânsito ser letal são cerca de 161 vezes maiores em ocorrências com características de contexto que contribuem ao máximo para aumentar

\footnotetext{
${ }^{8}$ Taxas referentes aos acidentes de trânsito em geral, isto é, não só aqueles ocorridos em rodovias federais.

${ }^{9}$ Para comprovar a relação entre dia da semana, período de ocorrência do acidente e ingestão de bebida, seria necessário utilizar a variável "causa do acidente". Entretanto, como já foi explicitado anteriormente, tal variável foi descartada em razão da baixa qualidade da informação.
} 
a probabilidade de óbito das vítimas, em relação a ocorrências com características de contexto que tendem a minimizar essa probabilidade.

Por outro lado, para acidentes com as mesmas características de contexto, foi observado que, em média, as chances de letalidade são, pelo menos, 66 vezes maiores para vítimas com características que elevam a probabilidade de óbito, em relação a vítimas com características que a minimizam.

Em face do exposto, concluiu-se que tanto as características de contexto dos acidentes de trânsito quanto as características de suas vítimas possuem grande influência na letalidade destes eventos. Tal resultado enriquece o debate sobre as mortes por esta causa, tantas vezes marcado exclusivamente pela culpabilização das vítimas e pouco por condições exógenas aos usuários das rodovias. É de suma importância conscientizar pedestres, condutores e passageiros sobre comportamentos perigosos no trânsito, tais como a associação entre álcool e direção, o não uso de dispositivos de segurança (como cinto de segurança, para passageiros de automóveis e caminhões, e capacetes, para motociclistas e ciclistas) e o uso de celular ao volante, fator que a cada ano ocasiona mais acidentes com vítimas fatais. Porém, conhecer mais sobre as condições de contexto dos acidentes que têm como resultado final o óbito de uma ou mais pessoas, tais como tipo de pista, fase do dia e dia da semana de ocorrência, permite a adoção de ações preventivas mais assertivas, que podem complementar as campanhas já realizadas e reduzir a mortalidade por esta causa evitável.

\section{Referências}

ANDRADE, S. M.; MELLO JORGE, M. H. P. Características das vítimas por acidentes de transporte terrestre em município da Região Sul do Brasil. Revista de Saúde Pública, v. 34, n. 2, p. 149-156, 2000. Disponível em: 〈http://www.journals.usp.br/rsp/article/view/24997〉. Acesso em: 10 maio 2017.

ABREU, A. M. M. et al. Uso de álcool em vítimas de acidentes de trânsito: estudo do nível de alcoolemia. Revista Latino-Americana de Enfermagem, v. 18, n. especial, p. 513-520, 2010. Disponível em: 〈http://www.scielo.br/pdf/rlae/v18nspe/a05v18nspe〉. Acesso em: 08 nov. 2017.

BACCHIERI, G.; BARROS, A. J. D. Acidentes de trânsito no Brasil de 1998 a 2010: muitas mudanças e poucos resultados. Revista de Saúde Pública, v. 45, n. 5, p. 949-63, 2011. Disponível em: 〈http:// www.scielo.br/pdf/rsp/v45n5/2981〉. Acesso em: 10 dez. 2018.

BARROS, A. J. D. et al. Acidentes de trânsito com vítimas: sub-registro, caracterização e letalidade. Cadernos de Saúde Pública, v. 19, n. 4, p. 979-986, 2003. Disponível em: 〈http://www.scielo. $\mathrm{br} / \mathrm{pdf} / \mathrm{csp} / \mathrm{v} 19 \mathrm{n} 4 / 16848$.pdf $>$. Acesso em: 17 maio 2017.

BECK, L. F.; DELLINGER, A. M.; O'NEIL, M. E. Motor vehicle crash injury rates by mode of travel United States: using exposure-based methods to quantify differences. American Journal of Epidemiology, v. 166, n. 2, p. 212-218, 2007. Disponível em: 〈https://academic.oup.com/aje/ article/166/2/212/98784/Motor-Vehicle-Crash-Injury-Rates-by-Mode-of-Travel>. Acesso em: 23 out. 2016.

BLAIZOT, S. et al. Injury incidence rates of cyclists compared to pedestrians, car occupants and powered two-wheeler riders, using a medical registry and mobility data, Rhône County, France. Accident Analysis \& Prevention, v. 58, p. 35-45, 2013. Disponivel em: 〈http://www.sciencedirect. com/science/article/pii/S0001457513001619〉. Acesso em: 23 out. 2016. 
BRASIL. Secretaria de Assuntos Estratégicos da Presidência da República. Instituto de Pesquisa Econômica Aplicada. Acidentes de trânsito nas rodovias federais brasileiras: caracterização, tendências e custos para a sociedade. Brasília, 2015a. Disponível em: 〈http://www.ipea.gov. br/portal/index.php?option=com_content\&view=article\&id=26277〉. Acesso em: 23 out. 2016.

Polícia Rodoviária Federal. Manual de Atendimento de Acidentes de Trânsito. Brasília, 2015b. Disponível em: 〈http://www.consultaesic.cgu.gov.br/busca/dados/Lists/ Pedido/Attachments/432155/RESPOSTA_PEDIDO_MPO\%20015\%20-\%20Atendimento\%20 de\%20Acidentes.pdf . Acesso em: 28 abr. 2017.

CABRAL, A. P. S.; SOUZA, W. V.; LIMA, M. L. C. Serviço de atendimento móvel de urgência: um observatório dos acidentes de transportes terrestre em nível local. Revista Brasileira de Epidemiologia, v. 14, n. 1, p. 3-14, 2011. Disponível em: 〈http://bvsms.saude.gov.br/bvs/ is_digital/is_0211/pdfs/IS31(2)034.pdf〉. Acesso em: 17 maio 2017.

DARMA, Y.; KARIM, M. R.; ABDULLAH, S. An analysis of Malaysia road traffic death distribution by road environment. Sadhana - Academy Proceedings in Engineerig Sciences, v. 42, n. 9 , p.1605-1615, 2017. Disponivel em: 〈https://www.scopus.com/inward/record.uri?eid=2-s2.0$85023770460 \&$ do $i=10.1007 \% 2 f s 12046-017-0694-9 \&$ partnerl $D=40 \&$ md5 $=7523 \mathrm{a} 12 \mathrm{e} 0606881 \mathrm{~b}$ c4c4f4f5444f23f6>. Acesso em: 24 abr. 2019.

DESLANDES, S. F.; SILVA, C. M. F. P. Análise da morbidade hospitalar por acidentes de trânsito em hospitais públicos do Rio de Janeiro, RJ, Brasil. Revista de Saúde Pública, v. 34, n. 4, p. 367-372, 2000. Disponível em: <https://www.scielosp.org/scielo.php?pid=S0034$89102000000400009 \&$ script=sci_arttext\&tlng=>. Acesso em: 10 mar. 2018.

FARIA, E. O.; BRAGA, M. G. C. Proposals for controlling traffic accident risks for children and adolescents. Ciência \& Saúde Coletiva, v. 4, n. 1, p. 95-107, 1999. Disponível em: 〈http://www. scielo.br/scielo.php?pid=S1413-81231999000100008\&script=sci_arttext\&tlng=es>. Acesso em: 19 fev. 2018.

GANNE, N. Estudo sobre acidentes de trânsito envolvendo motocicletas na cidade de Corumbá e região, Estado do Mato Grosso do Sul, Brasil, no ano de 2007. Revista Pan-Amazônica de Saúde, v. 1, n. 3, p. 19-24, 2010. Disponível em: 〈http://scielo.iec.pa.gov.br/scielo.php?script=sci_ arttext\&pid=S2176-62232010000300003〉. Acesso em: 06 out. 2016.

HOSMER, D. W.; LEMESHOW, S. A goodness-of-fit test for the multiple logistic regression model. Communications in Statistics - Theory and Methods, v. 9, n. 10, p. 1043-1069, 1980.

KONG, C.; YANG, J. Logistic regression analysis of pedestrian casualty risk in passenger vehicle collisions in China. Accident Analysis and Prevention, v. 42, n. 4, p.987-993, 2010. Disponível em: 〈https://www.sciencedirect.com/science/article/pii/S0001457509003078?via\%3Dihub〉. Acesso em: 10 dez. 2018.

LEGAY, L. F. et al. Acidentes de transporte envolvendo motocicletas: perfil epidemiológico das vítimas de três capitais de estados brasileiros, 2007. Epidemiologia e Serviços de Saúde, v. 21, n. 2, p. 283-292, 2012. Disponivel em: «http://scielo.iec.pa.gov.br/scielo.php?pid=S167949742012000200011\&script=sci_abstract . Acesso em: 06 out. 2016.

LIMA, I. M. O. et al. Fatores condicionantes da gravidade dos acidentes de trânsito nas rodovias brasileiras. Brasília: Instituto de Pesquisa Econômica Aplicada (IPEA), 2008 (Texto para Discussão, n. 1344). Disponivel em 〈https://www.econstor.eu/handle/10419/91363〉. Acesso em: 11 maio 2017.

LIMA, L. C.; CRUZ JUNIOR, V. S. Estudo dos acidentes de trânsito no Brasil à luz da Pesquisa Nacional de Saúde 2013. In: XX ENCONTRO NACIONAL DE ESTUDOS POPULACIONAIS. Anais [...]. Foz do Iguaçu, Paraná: Abep, 2016. 
MALTA, D. C. et al. Análise das ocorrências das lesões no trânsito e fatores relacionados segundo resultados da Pesquisa Nacional por Amostra de Domicílios (PNAD) Brasil, 2008. Ciência \& Saúde Coletiva, v. 16, n. 9, p. 3679-87, 2011. Disponível em: 〈http://www.scielosp.org/scielo. php?pid=S1413-81232011001000005\&script=sci_abstract\&tlng=es〉. Acesso em: 13 out. 2016.

MARÍN-LEÓN, L. et al. Tendência dos acidentes de trânsito em Campinas. Cadernos de Saúde Pública, v. 28, n. 1, p. 39-51. jan. 2012. Disponível em: 〈http://www.scielo.br/pdf/csp/v28n1/05〉. Acesso em: 26 de mar. 2017.

MASSIE, D. L.; CAMPBELL, K. L.; WILLIAMS, A. F. Traffic accident involvement rates by driver age and gender. Accident Analysis and Prevention, v. 27, n. 1, p. 73-87, 1995.

MELLO JORGE, M. H. P. Acidentes de trânsito no Brasil: um atlas de sua distribuição. 2. ed. São Paulo: Abramet, 2013.

MORAIS, M. R. et al. Letalidade do acidente de trânsito na modernista Palmas/TO: uma abordagem econométrica. Informe Gepec, v. 18, n. 1, p. 156-176, 2014. Disponível em: 〈http://erevista.unioeste.br/index.php/gepec/article/view/7784>. Acesso em 02 fev. 2018.

OLIVEIRA, N. L. B.; SOUSA, R. M. C. Fatores associados ao óbito de motociclistas nas ocorrências de trânsito. Revista da Escola de Enfermagem da USP, v. 46, n. 6, p. 1379-1386, 2012. Disponível em: 〈http://www.journals.usp.br/reeusp/article/view/52826〉. Acesso em: 04 abr. 2017.

OLIVEIRA, Z. C.; MOTA, E. L. A.; COSTA, M. C. N. Evolução dos acidentes de trânsito em um grande centro urbano, 1991-2000. Cadernos de Saúde Pública, v. 24, n. 2, p. 364-372, 2008. Disponível em: 〈http://ref.scielo.org/h356wn〉. Acesso em: 19 fev. 2018.

ORGANIZACIÓN MUNDIAL DE LA SALUD (OMS). Accidentes del tráfico en los países en desarrollo. Série de Informes Técnicos 703. Ginebra: OMS, 1984.

PAIXÃO, L. M. M. M. et al. Óbitos no trânsito urbano: qualificação da informação e caracterização de grupos vulneráveis. Cadernos de Saúde Pública, v. 31, sup., p. S1-S15, 2015. Disponível em: 〈https://www.scielosp.org/article/ssm/content/raw/?resource_ssm_path=/media/assets/csp/ v31s1/pt_0102-311X-csp-31-s1-0092.pdf>. Acesso em: 10 dez. 2018.

PALMEIRA, G. Epidemiologia. In: ROZENFELD, S. (org.). Fundamentos da vigilância sanitária [online]. Rio de Janeiro: Editora Fiocruz, 2000, p. 135-194. ISBN 978-85-7541-325-8. Disponível em: 〈http://books.scielo.org/id/d63fk/pdf/rozenfeld-9788575413258.pdf〉. Acesso em: 10 dez. 2018.

RAKAUSKAS, M. E.; WARD, N. J.; GERBERICH, S. G. Identification of differences between rural and urban safety cultures. Accident Analysis \& Prevention, v. 41, n. 5, p. 931-937, 2009. Disponível em: 〈https://www.sciencedirect.com/science/article/pii/S0001457509001092〉. Acesso em: 26 abr. 2019.

SANTAMARIÑA-RUBIO, E. et al. Gender differences in road traffic injury rate using time travelled as a measure of exposure. Accident Analysis \& Prevention, v. 65, p. 1-7, 2014. Disponivel em:shttp:// www.sciencedirect.com/science/article/pii/S0001457513004776). Acesso em: 03 abr. 2017.

WORLD HEALTH ORGANIZATION (WHO). Global status report on road safety 2015. Geneva: WHO, 2015. Disponivel em: 〈http://www.who.int/violence_injury_prevention/road_safety_status/2015/ Summary_GSRRS2015_POR.pdf?ua=1〉. Acesso em: 06 out. 2016.

ZWERLING, C. et al. Fatal motor vehicle crashes in rural and urban areas: decomposing rates into contributing factors. Injury Prevention, v. 11, n. 1, p. 24-28, 2005. 


\title{
Sobre os autores
}

Gilvan Teles Barroso Junior é mestre em População, Território e Estatísticas Públicas pela Escola Nacional de Ciências Estatísticas (Ence) do IBGE.

Ana Carolina Soares Bertho é doutora em Demografia pela Universidade Estadual de Campinas (Unicamp). Pesquisadora e professora da Pós-Graduação em População, Território e Estatísticas Públicas da Escola Nacional de Ciências Estatísticas (Ence) do IBGE.

Alinne de Carvalho Veiga é doutora em Estatística Social pela Universidade de Southampton. Pesquisadora e professora da Pós-Graduação em População, Território e Estatísticas Públicas da Escola Nacional de Ciências Estatísticas (Ence) do IBGE.

\section{Endereço para correspondência}

\author{
Gilvan Teles Barroso Junior \\ Escola Nacional de Ciências Estatísticas (Ence/IBGE) \\ R. André Cavalcanti, 106, Bairro de Fátima \\ 20231-050 - Rio de Janeiro-RJ, Brasil \\ Ana Carolina Soares Bertho \\ Escola Nacional de Ciências Estatísticas (Ence/IBGE) \\ R. André Cavalcanti, 106, Bairro de Fátima \\ 20231-050 - Rio de Janeiro-RJ, Brasil \\ Alinne de Carvalho Veiga \\ Escola Nacional de Ciências Estatísticas (Ence/IBGE) \\ R. André Cavalcanti, 106, Bairro de Fátima \\ 20231-050 - Rio de Janeiro-RJ, Brasil
}

\section{Abstract}

Lethality of traffic accidents on Brazilian federal highways in 2016

Traffic accident mortality is a growing concern worldwide, recognized as a major public health problem and the leading cause of death among 15- to 29-year-olds (WHO, 2015).. In Brazil, in 2016, approximately 37 thousand people died as result of traffic accidents, 6,400 (17\%) of which took place in federal highways. Given the importance of these deaths, the aim of this article is to identify factors associated with the lethality of traffic accidents on Brazilian federal highways in 2016, considering not only the characteristics of the victims, but also the context of the occurrence of such accidents. To that end, a binomial logistic regression model was used. Results obtained from the statistical model showed that, on average, the chances of a traffic accident being fatal are higher for males, pedestrians, occurrences in the Northeast region, during Sundays, at dawn, in curves and rural areas, and become even higher for older victims.

Keywords: Accidents. Traffic. Lethality. Regression analysis.

\section{Resumen}

La letalidad de los accidentes de tránsito en las carreteras federales brasileñas en 2016 
La preocupación por la mortalidad por accidentes de tránsito ha aumentado en el mundo, en tanto es un importante problema de salud pública y la principal causa de muerte entre jóvenes de entre 15 y 29 años de edad (WHO, 2015). En Brasil, en 2016, aproximadamente 37.000 personas murieron a consecuencia de accidentes de tránsito, de las cuales 6400 (17\%) fallecieron después de accidentes en carreteras federales. Teniendo en cuenta la importancia de esas muertes, el objetivo de este artículo es identificar factores asociados a la letalidad de los accidentes de tránsito en las carreteras federales brasileñas en 2016 considerando, además de las características de las víctimas, información acerca del contexto en que se produjeron estos eventos. Para ello se utilizó un modelo binomial de regresión logística. Los resultados indican que, en la media, las posibilidades de que un accidente de tránsito sea letal aumentan para hombres, peatones, ocurrencias en la región Noreste, en los domingos, por la madrugada, en las curvas, en áreas rurales y para víctimas de edades más avanzadas.

Palabras clave: Accidentes de tránsito. Letalidad. Análisis de regresión.

Recebido para publicação em 12/12/2018

Aceito para publicação em 27/05/2019

\section{ANEXO 1}

Resumo dos tratamentos realizados nas variáveis selecionadas para análise da base de dados de acidentes de trânsito da PRF de 2016

\begin{tabular}{ll}
\hline Variáveis originais & Variáveis novas \\
\hline Estado físico & Estado físico \\
Ferido grave & Sobrevivente \\
Ferido leve & Sobrevivente \\
Morto & Morto \\
\hline Horário (dado em hh:mm:ss) & Horário \\
Entre 06:00:01 e 12:00:00 & Manhã \\
Entre 12:00:01 e 18:00:00 & Tarde \\
Entre 18:00:01 e 00:00:00 & Noite \\
Entre 00:00:01 e 06:00:00 & Madrugada \\
\hline Tipo de acidente & Tipo de acidente \\
Atropelamento de animal & Outros \\
Atropelamento de pessoa & Atropelamento de pessoa \\
Capotamento & Capotamento ou tombamento \\
Colisão com bicicleta & Colisão com bicicleta \\
Colisão com objeto fixo & Outros \\
Colisão com objeto móvel & Outros \\
Colisão frontal & Colisão frontal \\
Colisão lateral & Colisão lateral \\
Colisão transversal & Colisão Transversal \\
Colisão traseira & Colisão traseira \\
Danos eventuais & Outros \\
Derramamento de carga & Outros \\
Incêndio & Outros \\
\hline & \\
& \\
\hline
\end{tabular}




\begin{tabular}{|c|c|}
\hline Variáveis originais & Variáveis novas \\
\hline Queda de motocicleta, bicicleta ou veículo & Queda de motocicleta, bicicleta ou veículo \\
\hline Saída de pista & Saída de pista \\
\hline Tombamento & Capotamento ou tombamento \\
\hline Tipo de envolvido & Condição de envolvimento \\
\hline Cavaleiro & Outros \\
\hline Ciclista & Ciclista \\
\hline Condutor & Ocupante do veículo dado por "tipo de veículo" \\
\hline Passageiro & Ocupante do veículo dado por "tipo de veículo" \\
\hline Pedestre & Pedestre \\
\hline \multicolumn{2}{|l|}{ Tipo de veículo } \\
\hline Automóvel & Ocupante de automóvel \\
\hline Bicicleta & Ciclista \\
\hline Bonde / Trem & Outros \\
\hline Caminhão & Ocupante de caminhão \\
\hline Caminhão-tanque & Ocupante de caminhão \\
\hline Caminhão-trator & Ocupante de caminhão \\
\hline Caminhonete & Ocupante de caminhonete ou camioneta \\
\hline Camioneta & Ocupante de caminhonete ou camioneta \\
\hline Carroça & Outros \\
\hline Carro-de-mão & Outros \\
\hline Charrete & Outros \\
\hline Ciclomotor & Outros \\
\hline Micro-ônibus & Ocupante de ônibus ou micro-ônibus \\
\hline Motocicletas & Ocupante de motocicleta \\
\hline Motoneta & Ocupante de motoneta \\
\hline Motor-casa & Outros \\
\hline Não identificado & Outros \\
\hline Ônibus & Ocupante de ônibus ou micro-ônibus \\
\hline Quadriciclo & Outros \\
\hline Reboque & Outros \\
\hline Semirreboque & Outros \\
\hline Trator de esteiras & Outros \\
\hline Trator de rodas & Outros \\
\hline Trator misto & Outros \\
\hline Triciclo & Outros \\
\hline Utilitário & Outros \\
\hline UF & Região \\
\hline UF brasileiras e o Distrito Federal & Respectivas regiões do Brasil \\
\hline
\end{tabular}

Fonte: Polícia Rodoviária Federal, 2016. 


\section{ANEXO 2}

Resultados da estimação do modelo final

\begin{tabular}{|c|c|c|c|c|c|c|c|}
\hline \multirow[t]{2}{*}{ Variáveis } & \multirow[t]{2}{*}{$\beta$} & \multirow[t]{2}{*}{$\mathrm{EP}(\beta)$} & \multirow[t]{2}{*}{$z^{2}$} & \multirow[t]{2}{*}{$\operatorname{Pr}\left(>z^{2}\right)$} & \multicolumn{3}{|c|}{ IC $(\exp (\beta))$} \\
\hline & & & & & $\exp (\beta)$ & $\mathrm{LI}$ & LS \\
\hline Intercepto & $-3,98$ & 0,13 & 935,44 & 0,00 & 0,02 & 0,01 & 0,02 \\
\hline \multicolumn{8}{|l|}{ Idade } \\
\hline Idade centrada & 0,01 & 0,00 & 75,86 & 0,00 & 1,01 & 1,01 & 1,02 \\
\hline Idade centrada ao quadrado & $2,10 \mathrm{E}-04$ & 0,00 & 12,69 & 0,00 & 1,00 & 1,00 & 1,00 \\
\hline Idade centrada ao cubo & $-1,89 \mathrm{E}-06$ & 0,00 & 1,16 & 0,28 & 1,00 & 1,00 & 1,00 \\
\hline \multicolumn{8}{|l|}{ Sexo (ref: feminino) } \\
\hline Masculino & 0,36 & 0,04 & 91,18 & 0,00 & 1,44 & 1,34 & 1,55 \\
\hline \multicolumn{8}{|l|}{$\begin{array}{l}\text { Condição de envolvimento } \\
\text { (ref: ocupante de automóvel) }\end{array}$} \\
\hline Ocupante de bicicleta & 1,31 & 0,09 & 191,41 & 0,00 & 3,71 & 3,08 & 4,46 \\
\hline Ocupante de caminhão & 0,34 & 0,06 & 37,55 & 0,00 & 1,41 & 1,26 & 1,57 \\
\hline Ocupante de motocicleta & 0,64 & 0,04 & 219,48 & 0,00 & 1,90 & 1,74 & 2,07 \\
\hline Ocupante de ônibus & $-0,61$ & 0,11 & 30,65 & 0,00 & 0,54 & 0,44 & 0,67 \\
\hline Pedestre & 2,25 & 0,14 & 260,50 & 0,00 & 9,49 & 7,22 & 12,47 \\
\hline Outros & 0,34 & 0,12 & 8,03 & 0,00 & 1,41 & 1,11 & 1,78 \\
\hline \multicolumn{8}{|l|}{ Região (ref: Sudeste) } \\
\hline Norte & 0,46 & 0,07 & 48,92 & 0,00 & 1,58 & 1,39 & 1,80 \\
\hline Centro-Oeste & 0,36 & 0,05 & 49,41 & 0,00 & 1,44 & 1,30 & 1,59 \\
\hline Nordeste & 0,58 & 0,04 & 202,27 & 0,00 & 1,78 & 1,65 & 1,93 \\
\hline Sul & 0,10 & 0,04 & 5,43 & 0,02 & 1,10 & 1,02 & 1,20 \\
\hline \multicolumn{8}{|l|}{$\begin{array}{l}\text { Tipo de acidente } \\
\text { (ref: colisão frontal) }\end{array}$} \\
\hline Colisão traseira & $-1,54$ & 0,07 & 489,21 & 0,00 & 0,21 & 0,19 & 0,25 \\
\hline Colisão lateral & $-1,47$ & 0,07 & 400,48 & 0,00 & 0,23 & 0,20 & 0,27 \\
\hline Colisão transversal & $-1,20$ & 0,06 & 395,17 & 0,00 & 0,30 & 0,27 & 0,34 \\
\hline Atropelamento de animal & $-1,84$ & 0,14 & 161,75 & 0,00 & 0,16 & 0,12 & 0,21 \\
\hline Atropelamento de pessoa & $-1,59$ & 0,15 & 116,29 & 0,00 & 0,20 & 0,15 & 0,27 \\
\hline $\begin{array}{l}\text { Capotamento ou } \\
\text { tombamento }\end{array}$ & $-1,83$ & 0,08 & 548,36 & 0,00 & 0,16 & 0,14 & 0,19 \\
\hline $\begin{array}{l}\text { Queda de motocicleta, } \\
\text { bicicleta ou outro veículo }\end{array}$ & $-2,26$ & 0,11 & 414,37 & 0,00 & 0,10 & 0,08 & 0,13 \\
\hline Saída de pista & $-1,47$ & 0,06 & 639,28 & 0,00 & 0,23 & 0,20 & 0,26 \\
\hline Outros & $-1,16$ & 0,09 & 171,35 & 0,00 & 0,31 & 0,26 & 0,37 \\
\hline \multicolumn{8}{|l|}{$\begin{array}{l}\text { Tipo de pista } \\
\text { (ref: pista simples) }\end{array}$} \\
\hline Pista dupla & $-0,07$ & 0,12 & 0,32 & 0,57 & 0,93 & 0,73 & 1,19 \\
\hline Pista múltipla & $-0,01$ & 0,29 & 0,00 & 0,97 & 0,99 & 0,56 & 1,76 \\
\hline \multicolumn{8}{|l|}{$\begin{array}{l}\text { Dia da semana } \\
\text { (ref: segunda-feira) }\end{array}$} \\
\hline Terça-feira & $-0,01$ & 0,06 & 0,02 & 0,88 & 0,99 & 0,87 & 1,12 \\
\hline Quarta-feira & 0,08 & 0,06 & 1,78 & 0,18 & 1,09 & 0,96 & 1,23 \\
\hline Quinta-feira & 0,06 & 0,06 & 1,00 & 0,32 & 1,06 & 0,94 & 1,20 \\
\hline Sexta-feira & 0,04 & 0,06 & 0,50 & 0,48 & 1,04 & 0,93 & 1,17 \\
\hline
\end{tabular}


(continuação)

\begin{tabular}{|c|c|c|c|c|c|c|c|}
\hline \multirow[t]{2}{*}{ Variáveis } & \multirow[t]{2}{*}{$\beta$} & \multirow[t]{2}{*}{$\mathrm{EP}(\beta)$} & \multirow[t]{2}{*}{$z^{2}$} & \multirow[t]{2}{*}{$\operatorname{Pr}\left(>z^{2}\right)$} & \multicolumn{3}{|c|}{ IC $(\exp (\beta))$} \\
\hline & & & & & $\exp (\beta)$ & $\mathrm{LI}$ & LS \\
\hline Sábado & 0,17 & 0,05 & 9,47 & 0,00 & 1,18 & 1,06 & 1,32 \\
\hline Domingo & 0,30 & 0,05 & 31,70 & 0,00 & 1,35 & 1,22 & 1,50 \\
\hline \multicolumn{8}{|l|}{$\begin{array}{l}\text { Fase do dia } \\
\text { (ref: manhã 6:00 a 12:00) }\end{array}$} \\
\hline Tarde - 12:00 a 18:00 & $-0,00$ & 0,04 & 0,00 & 0,99 & 1,00 & 0,92 & 1,09 \\
\hline Noite - 18:00 a 0:00 & 0,34 & 0,04 & 66,93 & 0,00 & 1,40 & 1,29 & 1,52 \\
\hline Madrugada - 0:00 a 6:00 & 0,80 & 0,05 & 273,34 & 0,00 & 2,23 & 2,03 & 2,45 \\
\hline \multicolumn{8}{|l|}{$\begin{array}{l}\text { Traçado da via } \\
\text { (ref: cruzamento) }\end{array}$} \\
\hline Reta & 0,80 & 0,11 & 55,35 & 0,00 & 2,22 & 1,80 & 2,74 \\
\hline Curva & 0,83 & 0,11 & 55,53 & 0,00 & 2,29 & 1,84 & 2,84 \\
\hline \multicolumn{8}{|l|}{ Uso do solo (ref: urbano) } \\
\hline Rural & 0,88 & 0,04 & 557,95 & $2,35 \mathrm{E}-123$ & 2,41 & 2,24 & 2,60 \\
\hline \multicolumn{8}{|l|}{$\begin{array}{l}\text { Interação - tipo de } \\
\text { pista x tipo de acidente }\end{array}$} \\
\hline Colisão traseira x pista dupla & $-0,03$ & 0,15 & 0,05 & 0,83 & 0,97 & 0,72 & 1,30 \\
\hline Colisão lateral x pista dupla & $-0,73$ & 0,19 & 14,74 & 0,00 & 0,48 & 0,33 & 0,70 \\
\hline $\begin{array}{l}\text { Colisão transversal x pista } \\
\text { dupla }\end{array}$ & $-0,44$ & 0,18 & 6,06 & 0,01 & 0,64 & 0,45 & 0,91 \\
\hline $\begin{array}{l}\text { Atropelamento de animal x } \\
\text { pista dupla }\end{array}$ & 0,12 & 0,33 & 0,13 & 0,71 & 1,13 & 0,59 & 2,14 \\
\hline $\begin{array}{l}\text { Atropelamento de pessoa x } \\
\text { pista dupla }\end{array}$ & 0,40 & 0,15 & 6,77 & 0,01 & 1,49 & 1,10 & 2,02 \\
\hline $\begin{array}{l}\text { Capotamento ou } \\
\text { tombamento x pista dupla }\end{array}$ & $-0,17$ & 0,17 & 0,92 & 0,34 & 0,85 & 0,60 & 1,19 \\
\hline $\begin{array}{l}\text { Queda de motocicleta, } \\
\text { bicicleta ou outro veículo x } \\
\text { pista dupla }\end{array}$ & $-0,17$ & 0,20 & 0,67 & 0,41 & 0,85 & 0,57 & 1,26 \\
\hline Saída de pista x pista dupla & $-0,04$ & 0,16 & 0,06 & 0,81 & 0,96 & 0,71 & 1,31 \\
\hline Outros x pista dupla & $-0,23$ & 0,17 & 1,76 & 0,18 & 0,80 & 0,57 & 1,11 \\
\hline $\begin{array}{l}\text { Colisão traseira x pista } \\
\text { múltipla }\end{array}$ & $-0,16$ & 0,35 & 0,23 & 0,63 & 0,85 & 0,43 & 1,67 \\
\hline $\begin{array}{l}\text { Colisão lateral x pista } \\
\text { múltipla }\end{array}$ & $-0,19$ & 0,37 & 0,25 & 0,62 & 0,83 & 0,40 & 1,72 \\
\hline $\begin{array}{l}\text { Colisão transversal x pista } \\
\text { múltipla }\end{array}$ & $-0,37$ & 0,39 & 0,87 & 0,35 & 0,69 & 0,32 & 1,50 \\
\hline $\begin{array}{l}\text { Atropelamento de animal x } \\
\text { pista múltipla }\end{array}$ & $-9,41$ & 85,86 & 0,01 & 0,91 & 0,00 & 0,00 & $9,91 x$ \\
\hline $\begin{array}{l}\text { Atropelamento de pessoa x } \\
\text { pista múltipla }\end{array}$ & $-0,04$ & 0,34 & 0,02 & 0,90 & 0,96 & 0,49 & 1,88 \\
\hline $\begin{array}{l}\text { Capotamento ou } \\
\text { tombamento x pista múltipla }\end{array}$ & $-0,03$ & 0,49 & 0,00 & 0,95 & 0,97 & 0,37 & 2,53 \\
\hline $\begin{array}{l}\text { Queda de motocicleta, } \\
\text { bicicleta ou outro veículo x } \\
\text { pista múltipla }\end{array}$ & 0,57 & 0,40 & 2,04 & 0,15 & 1,76 & 0,81 & 3,84 \\
\hline Saída de pista x pista múltipla & $-0,07$ & 0,49 & 0,02 & 0,89 & 0,94 & 0,36 & 2,44 \\
\hline Outros x pista múltipla & 0,14 & 0,36 & 0,15 & 0,70 & 1,15 & 0,56 & 2,35 \\
\hline
\end{tabular}

Fonte: Polícia Rodoviária Federal, 2016. 